\title{
Tramas agroecológicas na colônia de Pelotas
}

Agroecologic plots in the Pelotas colony

\section{Patrícia dos Santos Pinheiro, Renata Menasche, Claudia Turra Magni e Carmen Janaína Machado}

\section{(2) OpenEdition}

Journals

\section{Edição electrónica}

URL: http://journals.openedition.org/aa/2852

DOI: $10.4000 /$ aa. 2852

ISSN: 2357-738X

\section{Editora}

Programa de Pós-Graduação em Antropologia Social (UnB)

\section{Edição impressa}

Data de publição: 1 julho 2018

Paginação: 93-122

ISSN: 0102-4302

\section{Refêrencia eletrónica}

Patrícia dos Santos Pinheiro, Renata Menasche, Claudia Turra Magni e Carmen Janaína Machado,

«Tramas agroecológicas na colônia de Pelotas», Anuário Antropológico [Online], v.43 n.1 | 2018, posto online no dia 26 maio 2019, consultado o 28 abril 2021. URL: http://journals.openedition.org/aa/2852 ; DOI: https://doi.org/10.4000/aa.2852

\section{c) (i) (9)}

Anuário Antropológico is licensed under a Creative Commons Atribuição-Uso Não-Comercial-Proibição de realização de Obras Derivadas 4.0 International. 


\title{
Tramas agroecológicas na colônia de Pelotas
}

\author{
Patrícia dos Santos Pinheiro \\ UFPB
}

Renata Menasche

UFPEL

Claudia Turra Magni

UFPEL

Carmen Janaína Machado

UFRGS

\section{Introdução}

Na colônia de Pelotas, região da Serra dos Tapes, ao sul do Rio Grande do Sul, uma densa composição de relações perpassa aspectos produtivos e socioeconômicos, fronteiras étnicas e alianças políticas, configurando, entre distâncias e proximidades, um espaço bastante complexo socialmente. Nele estão presentes agricultores com produção diversificada, convencionais e agroecológicos, fumicultores, pecuaristas, produtores mais capitalizados e mesmo empresas, as quais cultivam soja, arroz, eucalipto ou outros. Esses sujeitos se articulam a partir de interesses específicos, sejam voltados às inúmeras expressões da agricultura familiar, seja ao que se convencionou chamar de agronegócio, sem uma separação estrita. A essas características se entrecruzam as marcantes distinções étnicas presentes na região, que remetem a colonos de diferentes origens, brasileiros, quilombolas, povos indígenas e outros ${ }^{1}$.

Neste espaço rural complexo, em que, desde 2011, pesquisamos o tema da alimentação através da agenda de pesquisa Saberes e Sabores da Colônia, passamos a atentar também para os fluxos de materiais, as experiências entre pessoas e coisas, assim como as narrativas associadas a tais práticas e concepções - cerne do projeto Saberes e sabores, objetos e imagens da colônia ${ }^{2}$, que ora nos atém. Através do trabalho etnográfico foi possível observar, por exemplo, habitações matriarcais, cuidadas com afeto por mulheres ao longo de gerações ${ }^{3}$, pessoas e plantas benzidas, invenções, guardiania de saberes e relatos sobre as complexas 
relações interétnicas e seus sistemas classificatórios.

Mas são os processos criativos na agricultura agroecológica ${ }^{4}$ que aqui destacaremos, a partir de uma perspectiva antropológica, atenta às práticas em movimento, aos fluxos criativos e às tecnologias, invenções e adaptações na produção. Em vez de técnicas isoladas, objetos apartados ou materialidades em si, percebemos no modo como manejam cada exemplar arbóreo, composto biodinâmico, animal ou outros, assim como em seus saberes e suas práticas diárias, aquilo que Ingold (2012) identifica como processos vitais. É sobre eles que dirigimos nosso olhar, identificando improvisos e movimentos, sobre os quais não é cabível a pretensão de controle absoluto.

A necessidade de incorporar os aspectos sensíveis do trabalho de campo e de dinamizar e potencializar diversas formas de compartilhamento com nossos interlocutores desafiou-nos a recorrer a recursos visuais e audiovisuais ao longo de toda a pesquisa ${ }^{5}$. A partir de capacitação técnica e teórico-metodológica, estes recursos potencializaram o registro e a análise de descrições e demonstrações de usos de objetos vinculados à produção e à alimentação. As imagens resultantes também contribuíram para evidenciar a indissociabilidade entre coisas, pessoas, ambientes, memórias, percepções e experiências. Dentre outras temáticas correlacionadas, memórias de práticas alimentares, territorialidades e aspectos produtivos foram abordados através de conversas informais e entrevistas semidirigidas.

Dois elementos aparentemente antagônicos constitutivos da agricultura familiar, especialmente da agroecologia, serão enfocados: a valorização de elementos considerados antigos, que estariam "se perdendo", e a busca simultânea por invenções e novidades. Por essa configuração desestabilizadora da dicotomia entre antigo e novo, observamos a busca por continuidades nas formas de engajamento cotidiano no ambiente. Isto vem reforçar resultados de pesquisa precedente (Pinheiro, 2010), que analisou o modo como plantas, produtos homeopáticos, biofertilizantes, animais, pessoas e instituições conformam uma rede de relações vinculada pela produção de base ecológica, mobilizando e modificando percepções e sentidos.

As aproximações prévias em pesquisas e espaços de discussão na região de Pelotas nos levaram à família Schiavon, agricultores da colônia São Manoel, município de Pelotas, cuja sintonia com plantas e animais, com técnicas empregadas e modificadas e com tecnologias criadas e multiplicadas evidencia um 
engajamento que vai além do sujeito individual e extrapola os limites da propriedade rural da família. Na pesquisa aqui apresentada, a relação desta família não se deu apenas no âmbito de sua propriedade, mas para além dela. Isto se verifica tanto pela indicação de uma rede de interlocutores para tratar dos objetos da colônia, quanto pela participação próxima e dialógica que Luana, a filha do casal Márcia e Nilo Schiavon ${ }^{6}$, manteve com a equipe, no desenrolar e desdobramentos da etnografia.

Se bem há preocupação em transformar a unidade de produção familiar em uma redoma, para evitar sua contaminação pela produção convencional do entorno, esta família se fortalece com sua inserção em um emaranhado de interações, na região e para além dela, materializadas na recepção de visitantes, parceiros ou participantes dos inúmeros cursos e mutirões realizados na propriedade, na exposição das invenções ou ainda na realização de intercâmbios e cursos em outras regiões do Rio Grande do Sul e do Brasil. Essas formas de engajamento são assumidas a partir de uma multiplicidade de perspectivas, em que circulam e são produzidas formas de conhecimento que modificam as estratégias de vida locais e que se fortalecem entre si.

Assim, a um olhar sobre o cotidiano prático dos agricultores em sua propriedade rural, devemos associar estratégias e dispositivos coletivos que permitem a continuidade da produção agroecológica. Diante desse quadro e na sequência de uma breve descrição da Serra dos Tapes e apresentação do contexto em que se inserem os Schiavon, refletiremos sobre as estratégias de criatividade e as tecnologias desenvolvidas no âmbito desta família rural, para, a partir daí, conduzir a atenção a dois processos em curso em sua propriedade: o sistema de agrofloresta e o preparo de compostos biodinâmicos.

\section{A Serra dos Tapes e o contexto do estudo}

O espaço rural de Pelotas está inserido na Serra dos Tapes, denominação associada ao contexto histórico de sua ocupação por índios Tapes, pertencentes à família linguística Tupi Guarani. Do final do século XVIII até meados do século XIX, o atual município de Pelotas (na época denominado São Francisco de Paula) se destacou pelo papel econômico assumido com a ascensão da fabricação do charque (Salamoni; Waskievicz, 2013), carne conservada com o dessecamento pela salga e exposição ao sol. Movida pela presença intensa de mão de obra negra cativa, a cadeia produtiva saladeiril conectava desde estâncias 
agropastoris em municípios vizinhos (principalmente nas terras baixas da Planície Costeira), até as dezenas de estabelecimentos industriais charqueadores de Pelotas, que abasteciam o comércio interno colonial com o charque (Osório, 2007). Na Serra dos Tapes, com áreas de mata e terreno íngreme que se mantinham pouco povoados, lavradores nacionais e cativos desenvolviam atividades agrícolas e pastoris a serviço dos charqueadores (Zarth, 2006), além de ser reduto de cativos fugitivos, os quais formaram dezenas de quilombos, muitos dos quais se consolidaram e permaneceram até a atualidade.

A partir de 1848, a Serra dos Tapes foi também ocupada por colonos imigrantes de origens diversas (como pomeranos, alemães, italianos, franceses etc.) através de processo incentivado pelo Governo Geral, resultando em significativa modificação da estrutura fundiária regional. Nas terras de planície, em áreas de grande extensão, desenvolveu-se, além da pecuária de corte, a produção de arroz, enquanto na região serrana consolidar-se-iam as pequenas propriedades familiares, marcadas pela diversidade de cultivos, com produção de milho, feijão, batata, entre outros. Já no século XX, a implantação de indústrias de beneficiamento (o cultivo de pêssego, em especial) alcançaria importância na economia regional, embora já não apresente o mesmo vigor (Salamoni; Waskievicz, 2013). Nas últimas décadas, cabe destaque à expansão do cultivo de fumo na região, em estreita vinculação à indústria fumageira.

Entre o final da década de 1980 e início da década de 1990, a família Schiavon dedicava-se à produção convencional de pêssegos e à produção de- leite, atividades que, na narrativa atual, são avaliadas como de alta exigência de mão de obra e baixo retorno econômico. Após um evento de contaminação por agrotóxicos (o relato assemelha-se ao de muitos agricultores da região), decidiram-se pela conversão ecológica de sua propriedade. Nas palavras do agricultor, registradas por Pinheiro (2015:281):

Então acabei adoecendo, e quando meus filhos nasceram, o Robinson e a Luana, eu estava numa sala do hospital, e eles nasceram na outra. Foi em 1988. Então, a trajetória mudou muito, a forma de pensar e tudo. Como eu trabalhava com veneno, e tava no hospital por causa do veneno, e aquelas crianças nascendo, amanhã ou depois eles iam crescer e eu não tinha ideia de mudar de atividade, e eles iam me pedir um pêssego para comer e eu ia ter que dizer que não poderia dar porque eu tinha botado veneno. Então foi uma coisa que já deu aquele estalinho, né? E isso aí, depois quando surgiu essa ideia de traba- 
lhar com produção orgânica em 1993, nós fomos uma das primeiras famílias a entrar nesse projeto, em Pelotas.

A família teve apoio de organizações religiosas que já então atuavam na perspectiva da agricultura de base ecológica, tais como a Igreja Episcopal Anglicana, a Comissão Pastoral da Terra - CPT (vinculada à Igreja Católica) e o Centro de Apoio e Promoção da Agroecologia - CAPA (associado à Igreja Luterana). Algumas dessas organizações estão presentes na região desde a década de 1970, atuando nas lutas dos pequenos agricultores diante das consequências do processo de modernização conservadora. Desse modo, questões referentes a práticas de manejo agrícola e preservação ambiental - que, mais tarde, viriam a confluir no que se conformaria como agroecologia - iniciavam a composição da agenda do que se constituía enquanto agricultura familiar ${ }^{7}$.

Mas o engajamento a estas formas de produção não se reduz à adesão a uma proposta técnica ou a práticas recomendadas de manejo. Faz também parte do processo a sua capilaridade entre os agricultores, através de laços de parentesco, amizade e parceria, bem como de inserção em relações de mercado - ou seja, sua aderência ao universo da colônia e da agricultura familiar. Nesse contexto, foi um marco a criação, em 1995, da Associação Regional dos Produtores Agroecológicos da Região Sul (Arpa-Sul), da qual a família Schiavon participou ativamente. Sobre sua constituição, Nilo enfatiza não se tratar de apoio, mas, sim, de parceria:

É outra visão. É não ficar na dependência, que é o projeto inicial, né? Desde que se formou a Associação, que nós éramos chamados de revolucionários, de loucos, de bagunceiros. Para conseguir as primeiras ordens para trabalhar aqui na cidade [Pelotas], a primeira feira a gente conseguiu invadindo, para conseguir ter o nosso espaço (...). Não queriam deixar por nada, faziam de tudo para a gente desistir, mas estamos lá até hoje. A gente é teimoso por natureza. (Pinheiro, 2015:290).

Disruptivo e corajoso, com a marca de quem por vezes se sente na contramão do mundo, esse posicionamento foi sendo mantido e remodelado ao longo dos anos. Atualmente, a Arpa-Sul conta com cerca de 30 famílias associadas ativas e há ainda outras organizações de agricultores na região, como a Cooperativa Sul Ecológica, com mais de 200 cooperados. Destarte, em um ambiente técnico no qual a ênfase se centra em técnicas calcadas em aumentos de produtividade e em cultivos de comodities, parte de um processo de transformação, 
estas famílias foram desenvolvendo, replicando e consolidando em suas propriedades a teimosia da produção agroecológica no país que mais consome agrotóxicos no mundo (Pignati et al., 2017).

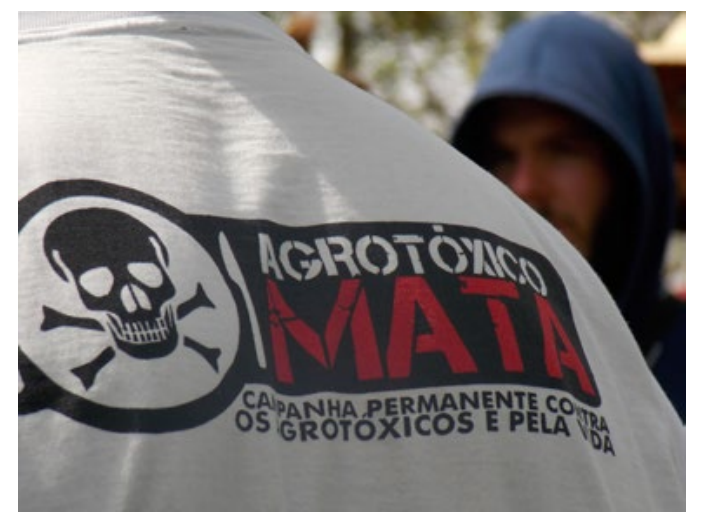

Figura 1: Camiseta de Nilo Schiavon. Fonte: Luana Schiavon, 2016.

Adequando as técnicas e práticas às suas lógicas de uso (mais do que a uma ideia estrita de produtividade), agricultoras e agricultores também fomentam a multiplicação do conhecimento ali construído, participando de feiras, de encontros de agroecologia, promovendo cursos na propriedade, recebendo escolas e estudantes da universidade para mutirões, realizando o trabalho da feira e da manutenção da associação e ainda participando da certificação participativa da Rede Ecovida (Pinheiro, 2010). Em um recriar constante, há ainda a busca de oportunidades de formação fora da região, influenciando a constituição e consolidação de práticas vinculadas à agroecologia e trazendo mais autonomia nas suas escolhas. Disseminadas por organizações e por agricultores, elas são selecionadas e reinterpretadas, a partir de suas vivências e conhecimentos.

Oliveira, Schneider e Marques (2017:87), ao abordarem esse tema, propõem uma análise a partir da interconexão entre "uma abordagem que reconhece e destaca o papel da prática agrícola como lócus e objeto de produção de novos conhecimentos e inovações e a abordagem da contextualização de conhecimentos". Assim, esses autores entendem que as diferentes formas de conhecimento - mesmo o científico, frequentemente revestido de um "filtro" de suposta neutralidade - fazem parte de um processo dinâmico, fruto do cotidiano de interações e acomodações entre diferentes atores sociais. Sem negar as contribuições das inovações oriundas de uma ciência "moderna”, em especial aquelas volta- 
das para o rural, os autores enfatizam a importância de uma epistemologia da prática, tanto quanto do contexto coletivo em que trocas e intercâmbios estimulam as inovações, seus usos e reapropriações.

Dado serem consideradas insuficientes as pesquisas voltadas a inovações na agricultura familiar, especialmente a de base ecológica, Oliveira, Schneider e Marques (2017) apontam como significativo, além da presença de instituições de pesquisa e desenvolvimento, o aporte dos próprios agricultores e de organizações parceiras, com seus técnicos, destacando a criatividade e reflexividade que caracterizam essa prática, vistas frequentemente como forma de interpretação e enfrentamento dos conflitos do mundo ${ }^{8}$. É nesse quadro e visando auxiliar questões básicas de uma produção diversificada e de seu beneficiamento, que fluxos criativos se desenvolvem junto aos Schiavon.

\section{Estratégias de criatividade e técnicas: conhecimento em construção}

Em uma das visitas realizadas à propriedade dos Schiavon, dirigimo-nos à lavoura, onde existe um espaço coberto para guardar as invenções de Nilo, utilizadas no cotidiano de trabalho. Ele então contou que, desde criança, criava coisas, como seus próprios brinquedos, caminhões e retroescavadeiras de madeira. Com a transição para a produção agroecológica, na década de 1990, sentiu necessidade de criar ou adaptar ferramentas e máquinas, já que as comercializadas não são concebidas para seu modo de fazer agricultura.

Acostumado a ensinar aos inúmeros visitantes, oriundos de diferentes partes do país, que atualmente vêm conhecer o trabalho da família, Nilo propôs apresentar cada uma das invenções, as motivações para desenvolvê-las e os respectivos usos, para fins de nosso registro audiovisual. Da lavoura, seguimos para o galpão, onde ele detalhou as modificações feitas no trator recentemente adquirido e mostrou as invenções desenvolvidas para/na agroindústria.

Mas não é qualquer técnica, em busca de qualquer eficiência, que Nilo desenvolve. Se técnicas e tecnologias são construídas a partir de interesses determinados, fundamentadas em princípios científicos ou empíricos, de modo a responder à vontade de seres humanos de transformar seu ambiente, materializadas em procedimentos e ferramentas, elas também expressam significados e escolhas, que nem sempre tomam por critério a produtividade, a facilidade ou a rentabilidade. Além das condições nas quais são aplicadas, é preciso considerar sua abrangência, sua localização espaço-temporal e outras influências, como aspec- 
tos políticos, condições socioeconômicas e de trabalho, características buscadas na produção e na propriedade. A estas variáveis ainda se associam os paradigmas científicos estabelecidos no momento de sua formação, bem como seus contrapontos (Pinheiro, 2010).

Do hábito infantil de recriar o maquinário agrícola em seus brinquedos, Nilo manteve o desafio por criar inventos, agora voltados para o trabalho com a agroecologia:

A gente trabalhava com pêssego convencional, feijão, milho, e quando entrou a agroecologia, se mudou o trabalho, começamos a entrar para a linha das hortaliças. Como as hortaliças têm as sementinhas muito pequeninhas, a gente teve uma grande dificuldade de conseguir fazer o plantio dessas pequenas sementes. Então se começou a passar trabalho para semear, aí começou a aparecer a necessidade das ideias, de ter equipamentos que melhorassem nosso trabalho. Começou com o plantio da cenoura, que é uma semente muito miudinha, e quando era dia de vento, a gente semeava a lanço, acabava ter que encostar o nariz no chão, agachadinho, para semear. Complicava muito, doía a coluna, era um trabalho! Com o passar do tempo, [eu] disse: vai ter que melhorar, pois fica muito junta a semente, se perde muita semente, depois para fazer o raleio. Aí se furou uma latinha de fermento na época, e começou a semear com aquela latinha, já melhorou bastante a forma de plantio, só que a dor na coluna ainda continuava. E isso foi, todos os meses se fazia uma latinha de cenoura, se pegou aquela latinha e se amarrou ela numa forquilha, o que veio a facilitar muito o nosso trabalho de plantio de canteiro (Schiavon, 2016).

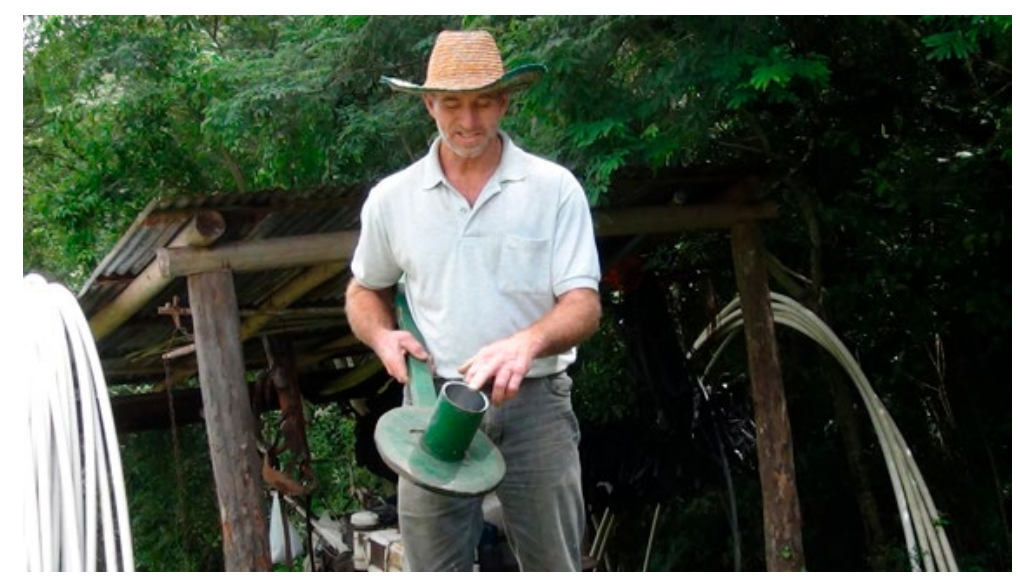

Figura 2: Nilo Schiavon mostra uma de suas invenções. Fonte: acervo da pesquisa, 2016. 
Conforme Nilo relatou na mesma ocasião, posteriormente seria criado um marcador para semeadura em linha, seguido de outro marcador para evitar o aparecimento de fungos e, "com isso aí, foi evoluindo... e depois apareceu a outra engenhoca”. E elas foram se sucedendo entre rotinas e produção de novos conhecimentos, adaptadas a cada novo desafio, tal como a presença de um fungo, a dor nas costas e assim por diante. Desse modo, na narrativa de Nilo a relação entre agroecologia e criatividade é intrínseca:

Esse ingresso na agroecologia, ele te faz pensar, todo o processo de mudança de paradigma te faz pensar. E esse "faz pensar", é o que faz criar. Essa é a metodologia do trabalho, é fazer o cérebro funcionar. Todo sistema de produção orgâanica é justamente isso aí: é tu pensar e agir como a natureza (Schiavon, 2016).

Quando argumenta agir como a natureza, Nilo reforça a ligação do que teria sido separado, a partir de uma ideia de modernidade. Junto com as plantas da propriedade, as ideias brotam, e coisas e pessoas coexistem, num mundo em fluxo perpétuo e não linear. Ou seja, não se trata de manipular uma superfície pré-formada de um mundo pronto, ou um substrato inerte, considerado um meio ou recurso. Trata-se, isso sim, de uma constante combinação de elementos que, neste caso, teriam sido considerados desconectados no processo de modernização da agricultura. Os efeitos desse processo são observados e sentidos para além da propriedade, como pondera Nilo: "[...] no ano passado fomos fazer um passeio, fomos lá no rio Camaquã. E aquele rio, uma beleza! Muito bonito. E não achamos um lambari para contar história, em um rio daquele tamanho. É sinal de alguma coisa errada" (Pinheiro, 2015:286).

Para Nilo, o primeiro passo da transição para a agroecologia não concerne a uma adaptação técnica, e sim ao modo de pensar a produção, baseado em princípios ecológicos de manejo do ambiente e em preocupações com a reprodução social da agricultura familiar. Em conjunto, esses elementos se colocam como alternativa ao modelo caracterizado como convencional, expressão da modernização agrícola. Assim, questões como homogeneização de cultivos, uso de agroquímicos, erosão genética e industrialização da agricultura são constantemente problematizados, fazendo emergir diferentes processos criativos.

O modelo convencional é também referenciado como tentativa de controle de fatores que escapam ao domínio humano, tais como o clima, a configuração 
do solo, a disponibilidade de nutrientes e água, entre outros - desde a modificação da composição genética das sementes até todo tipo de adubo ou insumo químico que molda a produção contemporânea.

Ao diferenciar controle e parceria, conhecimento externo e conhecimento construído localmente, Nilo chama a atenção para o fato de que o processo hegemônico de modernização agrícola acaba por ocasionar uma cisão entre a construção do conhecimento sobre a produção agrícola e a vida dos agricultores que dela dependem. Se a agricultura agroecológica não conta com as "facilidades" proporcionadas pelo uso de herbicidas, pesticidas, adubos sintéticos e outros, isso reflete tanto na produtividade como no tempo de trabalho despendido. Neste contexto, os desafios podem se repetir, de modo instável, diante das mudanças no mundo: o clima já não é o mesmo; as geadas são mais violentas; as chuvas não acontecem nos períodos e intensidade de antigamente; a legislação se modificou, trazendo exigências na certificação da produção; a agricultura convencional se generalizou, acabando por afetar fontes de água etc. No entanto, esses e outros elementos não agem de modo totalizante na vida de agricultores e agricultoras, que não somente reagem a eles, mas, sim, dão forma a tramas de vida.

Neste sentido, o status dos técnicos e instituições de pesquisas também passa a ser de parceria, ao tempo em que experiências compartilhadas são realizadas. Os próprios agricultores especializaram-se e desenvolveram técnicas e tecnologias específicas, de tal modo refinadas que foram possíveis apenas pela continuidade na construção (coletiva e individual) de cada espaço, modificado a cada safra, a cada colheita, a cada nova técnica experimentada, a cada conversa e intercâmbio realizados, em viagens ou no acolhimento de pessoas.

Mas, ainda que alcançado relativo equilíbrio, o meio jamais é estático. Há que pensar constantemente sobre como reagir a cada desafio, como tentar evitar o desequilíbrio do sistema, prevenir as doenças das plantas com caldas e produtos, tais como os homeopáticos ou os fertiprotetores (usados para distintos insetos ou fungos), ou ainda a simples cinza em pó, em calda ou misturada a outros materiais, que pode resolver problemas como um ataque de pulgões (Pinheiro, 2010). Assim sendo, se as práticas agroecológicas redefinem maneiras de produzir, também possibilitam ou promovem novos conhecimentos. Na escolha de determinadas técnicas e recusa de outras, há a abertura para um trabalho interpretativo, de ajuste de circunstâncias cotidianas a categorias gerais, tal como o enfrentamento de desafios impostos diante de questões ambientais. 
Considerando as trajetórias dos materiais, a agricultura de base ecológica exige o conhecimento das diferentes etapas do funcionamento local e do processo produtivo de vários cultivos, postos em relação. Em um conhecimento profundo, baseado em constantes experimentações feitas por agricultores e também pela confirmação, adaptação ou confrontação das informações recebidas por meio de técnicos e instituições de pesquisa, cada agricultora e agricultor, no contato cotidiano, vai moldando seu espaço a partir de suas vontades e prioridades, assim como do convívio e da interação com os conhecimentos apreendidos de outros lugares e experiências. As inovações são, assim, fundadas na observação, no contato, na experiência, ampliando as possíveis respostas para cada desafio na produção em seu laboratório aberto.

A cada visita, a propriedade dos Schiavon não é mais a mesma. Onde antes havia uma plantação de cenouras, passaram a cultivar couves, e assim por diante. Ao lado da agroindústria que atualmente produz sucos, há um local - em expansão - reservado para árvores trazidas de cada curso realizado fora da propriedade, guardando a memória dessas jornadas. Longe do ambiente de (suposto) controle de uma ciência própria da agricultura convencional, o local no qual são desenvolvidos esses processos criativos não é isolado, nem remete a objetos concebidos como desprovidos de vida, passíveis de manipulação somente pelo agente humano. Esse ambiente modifica-se a olhos vistos na medida em que há um caminhar que transforma, ao longo e não através de algo e que também é atravessado por fatores externos, como as geadas que, de tempos em tempos, afetam drasticamente a produção de pêssego.

Como evidenciado em trabalho realizado com agricultores da mesma região (Marques et al., 2015), a aproximação com a agroecologia decorreu de experiências de contaminações por agroquímicos, com sintomas como enjoos, dores de cabeça, vômitos e, inclusive a morte de animais, dependendo do produto. Como já mencionado, foi a hospitalização de Nilo que desencadeou sua reflexão existencial e a decisão da família em aderir à produção agroecológica. Se os agroquímicos são frequentemente referidos como venenos, que, além de caros, constituem impedimento para o consumo do alimento pela família, isso não significa que outros tipos de insumos sejam rejeitados. Em mediação diante de necessidades específicas, como em momentos de desequilíbrio ou na recuperação de solos degradados ou de composição específica, a prática agroecológica apoia-se em produtos e técnicas diversas, tais como adubação verde, biofertili- 
zantes, vermicompostagem, calda bordalesa, fumo, ervas, cinza, urina de vaca, esterco e óleos. Mais recentemente, os Schiavon incorporaram ainda compostos biodinâmicos, elaborados prioritariamente na propriedade, concebidos como um emaranhado de organismos vivos, um sistema cujo objetivo é a aproximação dos ciclos biológicos.

Pensando em processos e não em produtos, ao abordar conhecimentos tradicionais e formas de cultivo e manuseio específicas da Amazônia brasileira, Manuela Carneiro da Cunha (2012) salienta como elementos que, em uma divisão ontológica, seriam aparentemente pertencentes à natureza, são de fato produtores e produtos de relações sociais, sendo sua origem lembrada. Como exemplo, ela se refere às mulheres que cultivam mandiocas no médio e alto Rio Negro e no alto Juruá. Biologicamente adaptadas à forma de cultivo tradicional em toda a Amazônia, em que a derrubada anual de novas roças é seguida de queima e coivara, a autora relata que as mandiocas da roça formam uma sociedade em si, à qual a dona da roça deve estimular de várias maneiras, por exemplo, cultivando perto delas outras plantas para companhia e serviços, seja para abaná-las, para executar música ou fazê-las dançar.

Entre experiências sensoriais, extra-sensoriais e ancestrais, esse sistema de conhecimento relatado por Carneiro da Cunha, assim como o que é cultivado pela família Schiavon, traz possibilidades epistêmicas e ontológicas diversas, que desafiam o paradigma dualista da existência de uma natureza universal, observada sob diferentes pontos de vista culturais (do Outro). Ao invés disso, com Merleau-Ponty (1994), em sua Fenomenologia da Percepção, aprendemos a considerar a interpenetração do corpo vivo com a pulsação do mundo, em que ambos estão organicamente relacionados, formando o que ele chama de a carne do mundo. Desse modo, a atenção da percepção, própria ao cotidiano destes agricultores, é exercitada ativamente em suas experiências e engajamentos com o meio.

Assim, para além do conhecimento científico desenvolvido em laboratórios, é necessário levar em consideração o conhecimento tradicional, engendrado no dia a dia destes agricultores, particularmente rico na medida em que é mantido e transmitido através de gerações e expandido por populações diversas entre si. Para Carneiro da Cunha (2012), nas trocas de conhecimentos há a possibilidade de ocorrer escambo de produtos, achados e descobertas, de procedimentos de cuidados com ambientes naturais, sem que se dissolvam os protocolos de pesquisa e verificação de uns nos protocolos dos outros. Esses escambos são enten- 
didos como trocas, com resultados que cada sistema virá a usar em seu próprio regime, não em uma fusão deles. Assim, a autora argumenta que é necessário procurar compreender os sistemas de conhecimento, não somente os produtos; e que a ciência contemporânea deve praticar intercâmbios de resultados, sem colonizar seus sujeitos.

Não se trata, portanto, de mobilizar ou acionar determinados recursos, mas de promover e fazer parte de recombinações, buscar ou criar técnicas e tecnologias e adequá-las ao contexto ecológico local, além de realizar trocas de experiências para a geração de transformações, em um processo de engajamento contínuo entre o perceptor e seu ambiente, concebidos como inseparáveis e interdependentes, a partir do conceito gibsoniano de affordance:

As affordances são os significados dos traços do ambiente. É tudo aquilo que o ambiente oferece ao animal e inclui objetos manipuláveis, perigo, substâncias comestíveis, lugares para esconder-se, proteger-se do frio, do vento e do calor, o chão para pisar, andar, correr, as armas e os materiais para aquecimento. Tudo isso relativo às formas vivas e ontologicamente atado ao animal (Santaella, 2012:57).

Assim, é a interdependência dinâmica entre os seres e o ambiente que os liga a um ecossistema, minando a pretensa dicotomia entre o objetivo e o subjetivo, o objeto e a mente, pois, ainda conforme Santaella (2012), na perspectiva ecológica de Gibson, em seu nível mais elementar, a sobrevivência depende da percepção das affordances. Não é o caso, portanto, de identificar a existência de objetos, plantas, animais, artefatos, pessoas como componentes do mundo, tal como elementos expostos em um museu e separados por sua origem ou característica, mas antes, de perceber o mundo como uma cozinha, em que é preciso, de forma dinâmica e processual, aprender habilidades, como propõe Ingold (2012:35): "Na cozinha, as coisas são misturadas em combinações variadas, gerando nesse processo novos materiais que serão por sua vez misturados a outros ingredientes num processo de transformação sem fim”.

É como em uma cozinha, cheia de experimentações, que foram sendo desenvolvidos conhecimentos associados à transformação de sementes em árvores e seus frutos em produtos beneficiados, como sucos, vinhos e doces. Do mesmo modo, a captação de água da chuva ou máquinas para descascar abóbora e para despolpar frutas foram inventadas, adaptadas ou replicadas neste local. Por 
exemplo, o plantio de uva e fabrico de vinho, tradicional na família Schiavon há gerações, passou a ser acompanhado do beneficiamento da uva para suco. A agroindústria construída há poucos anos permite um maior aproveitamento das frutas que não são vendidas na feira, como bergamotas, laranjas e pêssegos, além das uvas, que são transformadas em produtos comercializados no período entre as safras.

Para separar a uva do cacho, antes de colocá-la na suqueira, Nilo inventou uma desengaçadeira manual, construída com materiais reutilizados e adequada ao diâmetro do grão da uva cultivada na propriedade. Em 2015, no Concurso do Inventor Rural, em São Paulo, essa máquina, exposta juntamente com a semeadeira prática e o multiprocessador de raízes e milho verde, foi premiada. Depois disso, por estímulo de Nilo, essas invenções circularam entre outros agricultores da região de Pelotas, passando por novas adaptações decorrentes deste processo de intercâmbio, o que nos incita a observar as coisas tornando-se coisas, em vez de considera-las em seus formatos finais, tal como o argumento de Ingold (2012).

Estas máquinas, assim como as técnicas produtivas relacionadas à agricultura de base ecológica, se constroem tendo por base múltiplos fatores entrecruzados, nem somente internos, tampouco restritos a demandas externas. Movidos pela busca de determinada concepção de eficácia, esses agricultores se aliam a produtos, cultivos, animais e demais substâncias na conformação do processo da produção. Nesse sentido, Fabio Mura, a partir de crítica ao conceito de técnica, elaborado por Leroi-Gourhan (1994, apud Mura 2011), argumenta que constituiria uma tendência técnica, tal como verifica na análise da produção/aquisição/transformação técnica entre os Guarani Kaiowa do Mato Grosso do Sul. O autor prossegue, enfatizando a relação entre experiências práticas e processos intelectuais na formação de estoques técnicos que, aliados a elementos culturais, possibilitam determinadas performances técnicas que interagem e disputam entre si, de modo dinâmico em um sistema sociotécnico.

É justamente essa busca de eficácia - não da produtividade ou do rebaixamento do custo da produção, mas, sim, da continuidade dos processos ecológicos na propriedade e de sua manutenção como uma referência para outros agricultores e demais visitantes - que fez o solo pedregoso e exaurido por conta de produções anteriores ganhar uma camada de terra viva, a partir de compostos, de adubação verde e outros. Fez também a produção se diversificar até chegar 
à composição de uma agrofloresta, além de garantir as condições de vida para diferentes animais: de tucanos e pássaros que "sabem que ali não tem veneno", passando por cavalos, galinhas do vizinho e minhocas.

\section{Emaranhados de vida: a agrofloresta e os compostos biodinâmicos enquanto processos vitais}

Sendo as propriedades dos materiais experimentadas em sua prática, os agricultores e agricultoras agroecológicos da região de Pelotas situam-se em processos criativos de engajamento com diferentes elementos e com as organizações em que se inserem. Sem estabelecer uma segmentação entre a cultura material e os materiais, tal qual problematizado por Ingold (2011), a agricultura de base ecológica não se dá somente com a construção de técnicas que seriam imposição de uma representação mental para o material. O que o autor propõe, no lugar destas divisões, é pensarmos os fluxos do mundo de materiais, "dentro do qual os seres de todos os tipos, mais ou menos pessoa ou coisa, geram a existência, um do outro, de forma contínua e recíproca” (Ingold, 2011:56-57).

Através deste mundo em formação, buscaremos analisar algumas implicações das estratégias criativas que emergem desse processo e, a partir disto, o importante papel que assumem na medida em que se desenrolam, sem necessariamente contar com um objetivo final. Entendendo que seguir não é reproduzir, mas sim conduzir o pensamento à itinerância e interação de um mundo em aberto, que sempre apresenta algo mais a ser descoberto, abordaremos duas atividades recentemente desenvolvidas na propriedade dos Schiavon: a agrofloresta e o uso de compostos biodinâmicos.

Em pesquisa realizada ainda em 2009 junto à família Schiavon, destacaram-se os temas da contraposição aos monocultivos e da diversidade de plantações associada ao estímulo à horta, tida pela família como prática de resgate do costume de produzir os alimentos a serem por ela consumidos. Na época, além de listar os mais de 40 cultivos mantidos pela família em unidade produtiva menor que dez hectares, Nilo fez questão de explicar a concepção de uma distribuição e combinação de plantas em um mesmo espaço e ao mesmo tempo, evitando juntar as que, demandando os mesmos nutrientes ou sendo suscetíveis às mesmas pragas, não seriam compatíveis (Pinheiro, 2010). Atualmente, a agrofloresta potencializa essa diversidade, havendo um refinamento desses conhecimentos na área destinada pela família a esse sistema de cultivo, com muito zelo. 
Na busca de aproximação com sistemas naturais, a propriedade ficava com a aparência de um mato, visto que esses sistemas não seguem somente um ordenamento linear e tampouco contam com a usual retirada da sujeira (como são chamados os inços), seja devido à adubação verde (com plantas como mucuna preta, aveia, ervilhaca, crotalária, azevém, feijão-miúdo, feijão guandu), seja pelo posterior desenvolvimento da agrofloresta. Nesse sentido, tais sistemas diferem radicalmente de uma lavoura convencional. Aqui, a suposta sujeira é desejada, e o solo jamais fica descoberto. Segundo os preceitos da agricultura de base ecológica, essa sujeira deve ser incorporada ao solo, pois é através da matéria orgânica dessas plantas que ocorre tanto a reposição dos nutrientes retirados em cultivos anteriores ao solo, quanto a qualificação de solos de composição limitada como fora o caso da propriedade dos Schiavon, outrora pedregosa.

Com diferenciado potencial de absorção de nutrientes do solo, as plantas são manejadas de acordo com o período do ano e com a necessidade de adubação sentida pelos agricultores. Mas, mesmo pertencentes a espécies diferentes, nesses ambientes, elas agem coletivamente. Importância é dada às leguminosas, pelo fato de associarem-se a bactérias que fixam nitrogênio ao solo. Esporadicamente, são atacadas por fungos, pássaros, galinhas - da família ou de vizinhos. Podem ainda recorrer à compostagem e vermicompostagem, também técnicas de aproveitamento de matéria orgânica disponível no local, a exemplo do esterco, usado como adubo após período de decomposição, maturado com a ajuda de minhocas. Essas ações de manejo se abrem para rever os engajamentos e dar espaço para este emaranhado em crescimento, em que aquilo que é tido como insignificante ou residual tem espaço para desenvolver-se, os conhecimentos externos sendo postos à prova e interligados com os conhecimentos próprios de agricultoras e agricultores.

Os caminhos que seguem este conjunto de associações são acompanhados pelos agricultores, por exemplo, através de plantas indicadoras, que, com nascimento espontâneo, comunicam o estado nutritivo do solo. Esses indícios e informações são também trocados com técnicos e extensionistas, em momentos de intercâmbios. Mas esses dados não são simplesmente repassados e aceitos, pois necessitam de explicações condizentes com a realidade cotidiana, além de afinidade com suas experiências em relação àquelas plantas. 


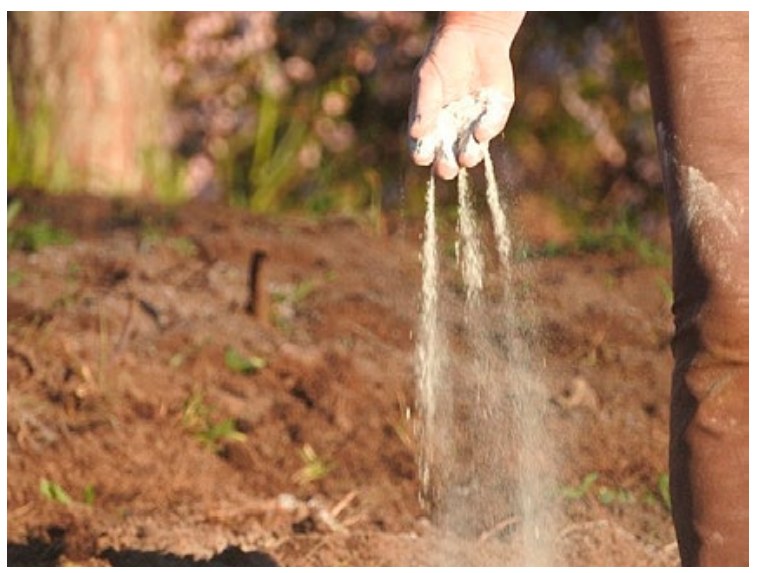

figura 3: Márcia Schiavon prepara a terra para o plantio de cenoura com pó de pedra.

Fonte: Luana Schiavon, 2016.

Já as hortaliças, cultivadas em local distinto daquele destinado à agrofloresta, após semeadas com as ferramentas adaptadas por Nilo, exigem a capina manual até que as plantas estejam mais desenvolvidas e resistam à presença de outras. Sem o emprego de herbicidas, todo tipo de planta cresce junto com elas. Nessas condições, a produção de base ecológica é considerada mais trabalhosa. Por outro lado, o crescimento vigoroso do inço é tratado como sinal de que há vida no solo e, consequentemente, de que os alimentos ali produzidos são mais saudáveis, expressando compensação pelo trabalho despendido.

Em um processo ao longo do qual as coisas são continuamente formadas, o sistema de agrofloresta, incomum na região e tendo sido estabelecido após intercâmbios em Goiás e com parceria da Empresa Brasileira de Pesquisa Agropecuária (Embrapa), demanda atualmente especial atenção da família. Nilo explica que ali foram plantadas três espécies de bergamota, caqui, uvaia, tomate arbóreo, araçá, além de acácias - que servem como aceleradoras iniciais do processo - e diversas outras árvores nativas da região. Sem conter a empolgação com a desenvoltura das árvores neste sistema, Nilo relata que, aos três anos de plantio, a uvaia já produzia seus pequenos frutos amarelos, sendo que o usual é produzir a partir de oito anos. A família estabeleceu como ideal $40 \%$ de sombra, sendo que o sistema, implementado há cinco anos, produz o ano inteiro.

Ao trazer essa experiência, as práticas humanas são aqui entendidas não apenas a partir das significações e sentidos das materialidades por intermédio das construções culturais da realidade, mas situadas nas experiências do envol- 
vimento corporal com o (e no) mundo, permeadas por fluxos de luz, sons e texturas do ambiente, que nos permitem descrevê-lo e compreendê-lo (Ingold, 2012). Assim, mais do que objetos separados que compõem o leque de invenções ou de produtos a serem comercializados na feira semanal da qual a família participa, trata-se de um conjunto de processos vitais - inversão essa que atenta antes para o processo de formação, do que para o produto final. Podemos, assim, pensar em cada fruto como parte de fluxo, da semente ao fruto colhido e dele ao nutriente absorvido por quem o consome, visto que ele cresceu em um solo adubado com esterco e adubos naturais, além da presença dos compostos biodinâmicos e da companhia de cenouras, cebolas, gansos, bananeiras e inúmeras pessoas, moradores e visitantes.

Nesse trajeto, porém, pode haver muitos percalços, pois a planta depende de condições favoráveis referentes a sol, temperatura, chuva, granizo etc., o que a insere em um conjunto de imprevisibilidades jamais resolvidas e que trazem a dimensão do desafio cotidiano de dar continuidade à produção. Como as plantas que crescem a partir de sua semente, o fluxo vital de cada um dos seres que habita este local forma um campo englobante de relações dentro do qual as formas surgem, vivem e desaparecem.

Apesar de comum a todos os organismos, habitar o mundo apresenta-se na singularidade das perspectivas e trajetórias dos diversos organismos em suas formas de engajamento. A interação com os animais, outro importante exemplo, é observada, sentida, ajustada e dependente da relação entre os seres. É o caso dos pássaros, inseridos na rede de parcerias da família: para eles é deixado seu quinhão das frutíferas, com a esperança (não autoridade) de que, por meio da dispersão das sementes, auxiliem na multiplicação da agrofloresta (e para além dela). Para atraí-los, foram plantadas frutíferas nativas, como açoita cavalo, guabiju, tarumã e murta. Assim, na constituição da agrofloresta, forma-se um emaranhado de linhas de crescimento de origens múltiplas, como uma teia viva que é criada e recriada pelos diferentes seres ali presentes. Nesta perspectiva, com Ingold (2013:16), “o que estamos acostumados a chamar de 'ambiente' pode, então, ser melhor visualizado como um domínio de emaranhamento”.

E é nesse quadro que a família Schiavon apropria-se de elementos adaptados a partir da agricultura biodinâmica, que tem suas bases na Antroposofia, desenvolvida ainda no século XIX por Rudolf Steiner, de origem austríaca. Contando com o preparo e uso de compostos biodinâmicos, tem base na homeopatia e em 
calendários astrológicos, como o lunar, entre outros.

Pouco figurando no repertório de técnicas dos agricultores de base ecológica da região de Pelotas, durante intercâmbios entre técnicos da Embrapa, do CAPA e de outras organizações e agricultores, tais compostos biodinâmicos foram elaborados na propriedade da família Schiavon. Após o tempo devido de maturação - período em que permanecem enterrados no solo -, os preparados são utilizados em diluição específica e aplicados na lavoura, "como um nutriente a mais no processo, no sistema de produção orgânica”, diz Nilo. Dentre os compostos produzidos pelos Schiavon, estão o Fladen (preparado em novembro de 2015 e desenterrado em maio do ano seguinte) e o chifre sílica, elaborado a partir de pedra de sílica moída dinamizada.

Ao experienciar a biodinâmica, são acionadas dimensões extra-sensoriais, para além das propriedades físicas e químicas do preparado, objeto de manuseio cuidadoso. Para Luana, filha de Nilo, a propriedade em si é um organismo vivo, em um universo de coisas que interagem, sendo a biodinâmica parte de uma benzedura, que em geral está vinculado ao processo de cura de enfermidades diversas e de proteção a malefícios externos. Por intermédio de ervas, cinza, água ou utensílios (mas não necessariamente), acompanhados de rezas e orações e, principalmente, da fé depositada no dom da cura, a família entende haver uma dimensão de cuidado com os diversos seres que habitam a propriedade, tornando-se a benzedura intrínseca às demais técnicas utilizadas.

A biodinâmica, para nós agricultores, ela já é uma benzedura também, tu aplica, tem todo um cuidado de preparo com os produtos e tal. E a forma de aplicação também que, né, essa aqui eu ainda apliquei, tu pega galhos de árvore e vai passando na plantação assim [gesticula com os braços]. É como se estivesse benzendo, realmente, a plantação, as plantas (Schiavon; Schiavon, 2016).

Para Luana e sua mãe, Márcia, trata-se de uma novidade, um processo de experimentação em curso na propriedade e cujos resultados positivos estão para além dela. Ao percebê-los , outras famílias têm se interessado, cientes de que se trata de um processo mais longo, diferente do imediatismo promovido por agroquímicos. Através deste ato de cuidado, afastam-se os males e possíveis danos a quem (ou àquilo a que) se quer bem, o que também demanda confiança: "não sei sé é os olhos de quem vê (...), tem de acreditar, né?”, diz Luana. Por meio dos compostos biodinâmicos, forma-se um vínculo entre a técnica - inovadora 
em relação às práticas agrícolas até então conhecidas e realizadas, seja no sistema convencional, seja no agroecológico - e a tradição, realizada por sua dimensão curadora, que abarca pessoas, plantas, animais e coisas. A agricultora explica que a biodinâmica possui como proposta a ativação da luz do sol para o crescimento da planta, citando, como exemplo, sua aplicação na lavoura de cenoura:

A gente semeou cenoura e já no ralinho, assim, colocamos o produto para a cenoura vir com mais força, vamos dizer assim, né. (...) E a outra (...) que nós fizemos aqui, foi com o esterco da galinha, a gente dinamizou com água e deixamos um tanto de dias assim, uns dois ou três dias, e aplicamos, também para ativar o crescimento da planta (Schiavon; Schiavon, 2016).

O processo de dinamização ocorre em uma bombona, com uma maneira de mistura específica, respeitando-se rigorosamente o modo de preparo para que haja o efeito esperado. Nessas experimentações, há uma relação que não se restringe a falar sobre, mas a construir com. Nesse contexto, a própria construção do conhecimento se alarga e tem como base o engajamento entre organismos com vida em suas experiências em comum, possível pelo deslocamento do estatuto dos sujeitos de conhecimento: nem uma assimilação da natureza pela cultura, nem uma diluição ou apagamento da cultura na natureza, mas, sim, um compartilhamento (Steil; Carvalho, 2014). Sob esse ângulo, Luana (Schiavon; Schiavon, 2016) descreve a técnica de extensão do solo nas árvores (Figura 2), em que se aplica uma mistura da base em direção aos galhos, colada ao caule, com o intuito de ajudar a planta a viver, proporcionando maior contato com os nutrientes do solo:

Aplica o produto desde o chão até o caule assim em cima, por exemplo, aqui, se essa [árvore] estivesse feia, querendo morrer, aplica lá até em cima assim, tu vais colando esterco bovino, terra, alguma coisa assim. O que quer dizer é a extensão do solo até em cima, né. Então ela vai ter força, vai tirar daquele produto, as forças que ela precisa para seguir a vida dela, como se o solo estivesse até em cima assim, é muito interessante. (...) E aí a planta vai revigorando, ela vai indo (Schiavon; Schiavon, 2016). 

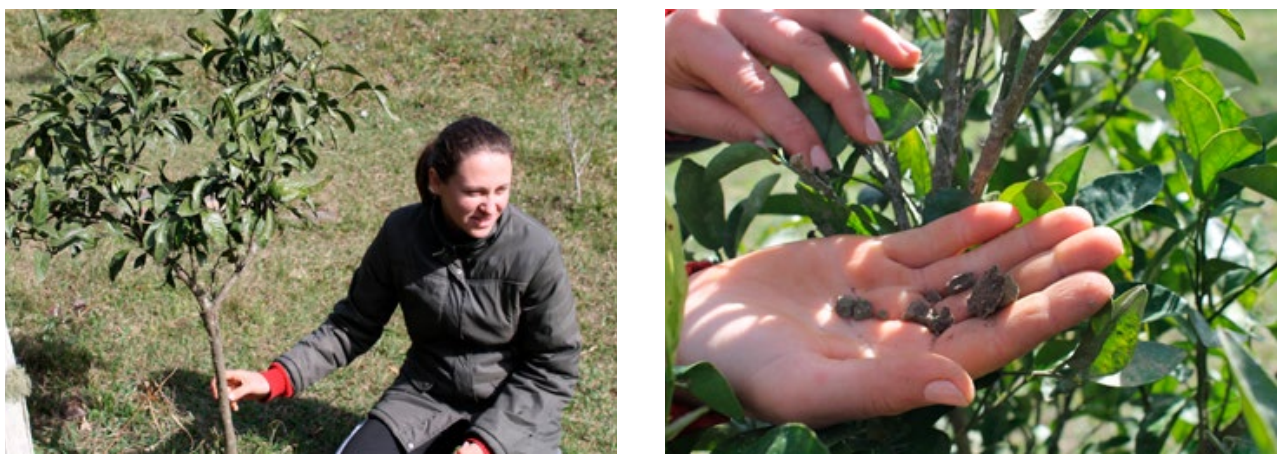

Figuras 4 e 5: Luana Schiavon mostra uma árvore em que foi feita a extensão de solo e, no detalhe à direita, mostra o produto que estava na árvore. Fonte: acervo da pesquisa, 2016.

A base utilizada para cobrir o caule da planta como extensão do solo é preparada com terra dinamizada, contendo uma série de elementos - tais como esterco bovino, casca de ovo, pedra talco, além da própria terra - misturados e amassados intensamente com os pés e posteriormente aplicados nas árvores mais fracas. Luana reforça os efeitos positivos da biodinâmica:

A gente viu o biodinâmico como uma benzedura. Tu acreditas, ela dá certo, tu vês que dá, como foi o caso aqui das nossas plantas. A gente viu que elas estavam danificadas, que elas estavam fraquinhas, mas aí elas sobreviveram, né, estão revigorando. Então é tudo uma crença também, de tu acreditar e fazer com carinho, fazer bem feito. É tu trabalhar com a terra, para a terra, tu acreditar que dela vem, o sol também, vai reagindo nas plantas (Schiavon; Schiavon, 2016).

Steil e Carvalho (2014:168) apontam para "a constituição de um topos epistemológico", que se propõe a refletir sobre modos de pensar a construção do conhecimento sem restringir-se aos protocolos de uma ciência moderna, que por vezes se propõe universal. Isso a partir de perspectivas teóricas que se desafiam a abordar as possibilidades de compreender as relações com o mundo, a partir de modos ecológicos. Assim, tratam-se de epistemologias (no plural) locais - em contraste com uma ideia universal - e nas quais há uma abertura para relações não exclusivamente humanas.

Não se trata apenas de destacar as diferenças entre conhecimento científico e popular, mas de perceber como bastante limitado o distanciamento epistemológico entre ambos. Os autores apontam para a necessidade de um deslocamento 
epistemológico diante da separação entre "a experiência humana do mundo, o mundo em sua existência objetiva e o conhecimento do mundo" (Steil; Carvalho, 2014:163). Tomando a experiência como condição para o conhecimento, a família Schiavon se mostra aberta a novos saberes, técnicas, diálogos, propostas.

Para Luana, tal como na benzedura, a transição e o vivenciar a agroecologia envolvem mudança e confiança, no caso em busca de um equilíbrio do ecossistema, dentro do que ela identifica como ecológico, que sustenta e atravessa suas diferentes linhas de crescimento:

[...] onde tu passas de um tradicional para um ecológico, que é o caso daqui, né, não somente orgânico, mas já ecológico, tem dificuldades porque, por exemplo, os insetos tu vai tirar alimento dele, mas ele vai comer outra coisa. Já aqui não, aqui já tem o alimento para eles que a própria natureza plantou, entende? Então ele já não vai tanto na tua planta quanto tu só tivesses a planta, é equilíbrio, de estabilidade. É tu trabalhar a favor da natureza, é isso, mas leva um tempo, uns quantos anos para ti chegar nesse equilíbrio de tudo assim (Schiavon; Schiavon, 2016).

Essas novidades e "invenções" técnicas em suas práticas e formas de engajamento no ambiente são, assim, uma consequência de um projeto agroecológico.

\section{Algumas ponderações}

Os agricultores agroecologistas da região de Pelotas, organizados em associações e cooperativas, estabelecem na sua relação cotidiana de parceria uma importante argumentação para o modo como manejam os elementos naturais, que não se restringe a um simples recentramento na preservação ambiental. Se por um lado, uma série de demandas externas associadas à produção está presente através de discursos sobre a maneira mais correta de produzir (seja por meio da assistência técnica, da participação em espaços e fóruns de discussão na região ou outros), por outro lado, a conformação e o delineamento do cotidiano praticado em cada propriedade são construídos de acordo com códigos morais assumidos e com as urgências que se colocam no presente, formando múltiplas possibilidades.

O que estes agricultores e agricultoras agroecológicos mostram, ao trabalhar com a terra e para a terra, é que estão continuamente desenrolando suas vidas e, assim, construindo um mundo jamais acabado, que se recria a partir das estra- 
tégias traçadas no improviso: uma constante transformação. Viver e produzir em parceria com a terra e seus frutos - mesmo aqueles que não são voltados para os humanos e seus desejos - exige novas estratégias, escolhidas no vínculo com a produção agroecológica, de acordo com a concepção do que seja mais legítimo no momento, a partir das experiências vividas. Por isso a importância de considerarem não somente os elementos naturais, a sociedade ou os objetos, mas o envolvimento coletivo, permitindo que a reflexão sobre o modo como se maneja a produção, na contramão do mundo, seja intrínseco às experiências práticas que visam a uma mudança em termos de eficácia técnica.

Além disso, é uma produção associada à ideia de continuidade, no sentido de sustentar uma renda que permita a reprodução da propriedade e da família no meio rural, mantendo uma qualidade de vida considerada por eles como aceitável, em que a intensidade do trabalho não é necessariamente percebida como problema, na medida em que permite prescindir do desgaste causado por agroquímicos à saúde. Relaciona-se ainda à guardiania da propriedade em sentido amplo, permitindo a sucessão familiar, dentro dos valores e moralidades convenientes.

Ao contraporem-se a determinadas técnicas modernas, enfatizarem um modo de ver e interagir com o mundo em que as invenções são estimuladas e a diversidade é promovida, as técnicas consideradas no âmbito da agricultura como obsoletas ou ultrapassadas passam a ser valorizadas, sendo revividas sob uma nova perspectiva. Como destaca Luana, é "interessante de pensar, de ver, outras formas de voltar ao que era o natural, que hoje em dia as coisas não são mais naturais, tudo muito artificial, eu vejo assim”. Esse retorno ao natural, no caso, mais do que idealização, pode ser visto como reinserção do animado e do movimento na ordem do dia, desenvolvendo um conhecimento sintonizado com o processo de vida.

É na reinvenção das invenções, na abertura para a experiência, que outros caminhos são forjados e prioridades são modificadas. Nestes fluxos, vistos não somente como reativos, mas como processos de criação, esta família e outros agricultores agroecológicos que fazem parte da mesma rede desenvolvem, intercambiam e modificam uma série de invenções e transformações nos modos de plantio, nas formas de adubação e no aproveitamento por meio do beneficiamento da produção.

Entendemos aqui que agricultoras e agricultores investem em experimenta- 
ções, desenvolvendo e renovando as normas locais e as práticas diferenciadas de uso dos elementos disponíveis, com base em atividades de produção e de intercâmbio de conhecimentos. Com isso, no gerenciamento de suas propriedades, há saberes que emergem das práticas dessas famílias, reunindo elementos novos e antigos, fazendo ajustes ao longo de sua trajetória, com todo tipo de aprendizados, influências, necessidades e oportunidades.

A agricultura de base ecológica constitui conhecimento teórico e empírico cujos resultados afetam as maneiras de identificação, compreensão, expressão e relacionamento dos agricultores entre si, com e através dos materiais. Apesar de todas as dificuldades que permeiam o estabelecimento de processos emancipatórios na agricultura, podemos destacar novas concepções acerca da qualidade alimentar, das condições de vida, do avanço nos meios de comunicação e transporte, do processo de acumulação e consumo, das relações de trabalho e mercado, da valorização do meio rural, entre outros aspectos relacionados à região da colônia em que foram desenvolvidas nossas pesquisas.

Ante a problematização exposta, compreendemos que este processo não concerne somente à leitura ou interpretação da natureza feita pelos agricultores, mas que talvez possamos falar em um compartilhamento existencial mais amplo. Para além do núcleo familiar, parece haver um potencial dinâmico e transformador de todo um campo de relações, no interior do qual e de forma recíproca, diversos seres geram a existência uns dos outros, relacionando elementos do cotidiano com escolhas e posicionamentos recíprocos.

Recebido: 01/03/2018

Aprovado: 11/06/2018

Patrícia dos Santos Pinheiro é doutora em Ciências Sociais pelo Programa de Pós-graduação de Ciências Sociais em Desenvolvimento, Agricultura e Sociedade da Universidade Federal Rural do Rio de Janeiro (CPDA/UFRRJ), pós-doutoranda no Programa de Pós-graduação em Antropologia da Universi- 
dade Federal da Paraíba (PPGA/UFPB). Possui pesquisas em conflitos socioambientais, agroecologia, territorialidades, relações étnico-raciais, políticas de identidade. Contato: patriciasantspinheiro@gmail.com

Renata Menasche é doutora em Antropologia, professora do Programa de Pós-Graduação em Antropologia da Universidade Federal de Pelotas (PPGAnt/ UFPel) e do Programa de Pós-Graduação em Desenvolvimento Rural da Universidade Federal do Rio Grande do Sul (PGDR/Ufrgs), investigadora visitante do Instituto de Ciências Sociais da Universidade de Lisboa (ICS/UL), coordenadora do Grupo de Estudos e Pesquisas em Alimentação, Consumo e Cultura (Gepac), bolsista PQ/CNPq. Contato: renata.menasche@pq.cnpq.br

Claudia Turra Magni é doutora em Antropologia Social e Etnologia pelo Programa de Pós-Graduação em Antropologia da Universidade Federal do Rio Grande do Sul, professora do Programa de Pós-Graduação em Antropologia (PPGAnt/UFPel), coordenadora do Laboratório de Ensino, Pesquisa e Produção em Antropologia da Imagem e do Som (Leppais/UFPel). Publicou Images du Même et de l'Autre: ethnographie des ateliers artisitiques pour des personnes sans domicile à Paris (2011). Contato: clauturra@yahoo.com.br

Carmen Janaína Machado é doutoranda e mestre pelo Programa de Pós-Graduação em Desenvolvimento Rural da Universidade Federal do Rio Grande do Sul (PGDR/Ufrgs) e pesquisadora do Laboratório de Estudos Agrários e Ambientais da Universidade Federal de Pelotas (LEAA/UFPel). Tem interesse em pesquisas sobre política pública, consumo, gênero, agroecologia e assentamentos de reforma agrária. Contato: carmemachado3@yahoo.com.br

\section{Notas}

1. De acordo com Seyferth (1992: 80), "para o Estado, eram colonos todos aqueles que recebiam um lote de terras em áreas destinadas à colonização. Trata-se, portanto, de uma categoria administrativa (...), apropriada pelos imigrantes e usada até hoje como identidade básica mais geral dos agricultores de origem europeia, sendo dela excluídos aqueles chamados de caboclos ou brasileiros”. A categoria brasileiro é empregada localmente para denominar descendentes de portugueses, mas também negros ou indígenas, habitualmente compreendida a partir um sistema classificatório 
- e, assim, hierárquico - do qual fazem parte os demais grupos mencionados. Neste estudo, em coerência com o que se dá na região estudada, a colônia é entendida como espaço abrangente de vida e trabalho dos diversos grupos camponeses.

2. Este projeto, desenvolvido entre 2015 e 2016, contou com financiamento da Fapergs, vindo a somar-se a outros anteriormente apoiados por CNPq e Fapergs todos conduzidos pelo Grupo de Estudos e Pesquisas em Alimentação, Consumo e Cultura (Gepac, disponível em: <https: / /www.ufrgs.br/gepac/>. Acesso em: 23 jun. 2018), vinculado à Universidade Federal de Pelotas -, cujos resultados foram sistematizados em produtos imagéticos e coletânea de artigos (Menasche, 2015). Cabe mencionar que uma versão anterior deste artigo foi submetida à discussão no $41^{\circ}$ Encontro Anual da ANPOCS - realizado em 2017 -, no Grupo de Trabalho "O rural no Brasil contemporâneo: questões teóricas e novos temas de pesquisa”

3. Uma habitação matriarcal pode ser lida como uma casa/morada em que as linhagens maternas se destacam como o centro das interações consanguíneas, sendo a casa a materialidade de descendência e herança familiar que também carrega consigo a memória de mães, avós e outras ancestrais. A temática, no âmbito dessa pesquisa, foi abordada no ensaio fotográfico Tapera (Pinheiro et al., 2017).

4. Diante de distintas conceituações de agroecologia - como campo científico, como movimento que congrega diversos atores sociais ou outras -, utilizaremos o termo conforme atribuições locais e, em referências mais gerais, adotaremos o termo agricultura de base ecológica. Da mesma forma, as ideias de transição (agroecológica) ou conversão são usadas aqui de acordo com a concepção elaborada por nossos interlocutores e interlocutoras.

5. Destacamos o uso de recursos imagéticos nos procedimentos de campo, na análise e na restituição do material destas pesquisas, que resultaram em uma série de produtos visuais. Disponível em: <http: / / wp.ufpel.edu.br/saberesesaboresdacolonia/>. Acesso em: 23 jun. 2018, parcialmente, em: <https: / /leppais.wordpress.com/projetos/pesquisa-e-extensao/>. Acesso em: 23 jun. 2018.

6. Luana, exímia fotógrafa, além de trabalhar na propriedade da família, era, à época da pesquisa, aluna do curso de Educação no Campo da Universidade Federal do Rio Grande, no qual se formou em 2017. A família é ainda composta por Robinson (irmão gêmeo de Luana) e Rômulo (caçula), sendo que o primeiro mora em outra propriedade rural, também de base ecológica. Além disso, cabe menção à dona Nelda (in memoriam), a vó, que também participou da pesquisa (Schiavon et al., 2016).

7. Podem ser mencionadas também a Empresa Brasileira de Pesquisa Agropecuária 
(Embrapa) Clima Temperado, com a Universidade Federal de Pelotas (UFPel) e com a Empresa de Assistência Técnica e Extensão Rural (Emater).

8. Há uma série de trabalhos sobre a temática, constituídos no contexto de debates relacionados ao desenvolvimento rural ou em proximidade. Ver, entre outros, Sabourin (2001) e Ploeg e Wiskerke (2004).

\section{Referências bibliográficas}

CARNEIRO DA CUNHA, M. 2012. Questões suscitadas pelo conhecimento tradicional. Revista de Antropologia, 55(1): 439-464.

INGOLD, T. 2013. Repensando o animado, reanimando o pensamento. Espaço Ameríndio, v. 7(2)10-25.

2012. Trazendo as coisas de volta à vida: emaranhados criativos num mundo de materiais. Horizontes Antropológicos, 18 (37): 25-44.

2011. Materiais contra materialidade. In: . Estar Vivo: Ensaios sobre movimento, conhecimento e descrição. Petrópolis, RJ: Vozes, pp. 49-69.

MERLEAU-PONTY, M. 1994. Fenomenologia da percepção. (C. Moura, Trad.). 1 Ed. São Paulo: Martins Fontes (Texto original publicado em francês em 1945).

MARQUES, F.C.; KRONE, E.E.; CRUZ, P.P.; SCHNEIDER, M. 2015. Produzir e comer ecológico: saberes e viveres em transformação. In: MENASCHE, R. (Org.). Saberes e sabores da colônia: alimentação e cultura como abordagem para o estudo do rural. Porto Alegre: Editora da Ufrgs.

MENASCHE, R. (Org.). 2015. Saberes e sabores da colônia: alimentação e cultura como abordagem para o estudo do rural. Porto Alegre: Editora da UFRGS.

MURA, Fabio. 2011. De sujeitos e objetos: um ensaio crítico de antropologia da técnica e da tecnologia. Horizontes Antropológicos, 17(36), 95-125.

OLIVEIRA, D.; SCHNEIDER, S.; MARQUES, F. C. 2017. Contextualização e práticas criativas na agricultura ecológica de Ipê e Antônio Prado/RS: o biofertilizante Super Magro como objeto epistêmico. Desenvolvimento e Meio Ambiente, Curitiba, $41: 83-104$.

OSÓRIO, H. 2007. O império português no sul da América: estancieiros, lavradores e comerciantes. Porto Alegre: Editora da Ufrgs.

PIGNATI et al. 2017. Distribuição espacial do uso de agrotóxicos no Brasil: uma ferramenta para a Vigilância em Saúde. Ciência \& Saúde Coletiva, 22(10): 3281-3293.

PINHEIRO, P.; RODRIGUES, G. R.; SCHIAVON, L.; MENASCHE, R.; TURRA MAGNI, C.; BITTENCOURT, H. 2017. Exposição fotográfica “Tapera”. IXVisualidades. 
Sobral (CE) e Rio de Janeiro (RJ), Brasil.

PINHEIRO, P. 2015. Agricultura de base ecológica e sustentabilidade: entrevista com Nilo Schiavon. Norus, 3 (4): 279-291. . 2010. Saberes, plantas e caldas: a rede sociotécnica de produção de base ecológica no sul do Rio Grande do Sul. Dissertação de Mestrado, Universidade Federal do Rio Grande do Sul.

PLOEG, J. D. V. der; WISKERKE, J. S. C. (Org.). 2004. Seeds of transition: essays on novelty production, niches and regimes in agriculture. Assen: Van Gorcun.

SABOURIN, E. 2001. Aprendizagem coletiva e construção social do saber local: o caso da inovação na agricultura familiar da Paraíba. Estudos Sociedade \& Agricultura, 16 (1): 37-61.

SALAMONI, G.; WASKIEVICZ, C. A. 2013. Serra dos Tapes: espaço, sociedade e natureza. Tessituras, 1(1): 73-100.

SANTAELLA, L. 2012. Percepção: fenomenologia, ecologia, semiótica. São Paulo: Cengage Learning.

SCHIAVON, Nilo. Nilo Schiavon. Entrevista [22 mar. 2016]. Entrevistadores: Patrícia Pinheiro e Carmem Janaina Machado. Pelotas, colônia São Manoel, 2016. 22 vídeos MTS (30'12”). Entrevista concedida ao projeto de pesquisa Objetos e Imagens, Saberes e Sabores da Colônia.

SCHIAVON, Luana; SCHIAVON, Márcia. Luana Schiavon e Márcia Schiavon. Entrevista [19 jul. 2016]. Entrevistadores: Patrícia Pinheiro e Carmem Janaina Machado. Pelotas, colônia São Manoel, 2016. 26 vídeos MTS (22’58”). Entrevista concedida ao projeto de pesquisa Objetos e Imagens, Saberes e Sabores da Colônia.

SCHIAVON, L.; MACHADO, C. J.; PINHEIRO, P. S.; RODRIGUES, G. R.; MENASCHE, R.; TURRA MAGNI, C.; BITTENCOURT, H. 2017. Família Schiavon (ensaio fotográfico).

SEYFERTH, G. 1992. As contradições da liberdade: análise de representações sobre a identidade camponesa. Revista Brasileira de Ciências Sociais, n. 18: 78-95.

STEIL, C. A.; CARVALHO, I. C. M. 2014. Epistemologias ecológicas: delimitando um conceito. Mana, 20, (1): 163-183.

ZARTH, P. A. 2006. A estrutura agrária. In: PICCOLO, H. I. L.; PADOIN, M. M. (Org.). Império. 1 Ed. Passo Fundo: Méritos. 
Resumo: Este trabalho busca mostrar processos criativos no âmbito da agricultura agroecológica da região de Pelotas, Rio Grande do Sul, seguindo suas forças e fluxos e analisando, sob um olhar antropológico, tecnologias, invenções e adaptações na produção. A partir de pesquisa etnográfica realizada entre 2015 e 2016, foram reunidos relatos concernentes a atividades produtivas e relação entre novidades e valorização de práticas tradicionais, expandindo as possibilidades de trabalhar com e não somente na terra. Esses relatos foram produzidos, sobretudo, pela família Schiavon, agricultores da localidade de São Manoel, cuja sintonia com plantas e animais, com técnicas empregadas e transformadas e com tecnologias criadas e multiplicadas evidencia um engajamento com o ambiente que extrapola os limites de sua propriedade rural.

Palavras-chave: Conhecimentos Tradicionais; Técnica; Campesinato; Agroecologia.
Abstract: This work seeks to show creative processes within the scope of agroecological agriculture in the region of Pelotas, Rio Grande do Sul, following its strengths and flows and analyzing technologies, inventions and production adaptations, under an anthropological approach. From the ethnographic research carried out from 2015 to 2016, we have gathered reports concerning the productive activities and the relationship between new features and promotion of traditional practices, expanding possibilities of working with, and not only on earth. These reports have been made mostly by the Schiavon family, farmers from the village of São Manoel, whose fine tuning with plants and animals, with techniques employed and transformed and with technologies created and multiplied show an engagement and commitment with the environment, going beyond the limits of their agricultural property.

Keywords: Traditional knowledge; Technique; Peasantry; Agroeco$\log$. 